\title{
Perforan göz yaralanmasına ikincil travmatik kataraktlarda katarakt cerrahisi sonuçları
}

The results of cataract surgery in traumatic cataracts secondary to perforating eye injury

Emine Doğan, Erkan Çelik, Nilgün Özkan Aksoy, Burçin Köklü Çakır, Özlem Bursalı

Gönderilme tarihi:02.02.2019

Kabul tarihi:18.04.2019

\section{Özet}

Amaç:Perforan göz yaralanmasına ikincil travmatik katarakt gelişen olgularda katarakt cerrahisi sonuçlarının değerlendirilmesi.

Gereç ve Yöntem: Çalışmada 2015-2018 yılları arasında perforan göz yaralanmasına ikincil travmatik katarakt nedeniyle cerrahi uygulanan olguların dosyaları geriye dönük olarak değerlendirildi. Hastaların yaş, cinsiyet, yaralanma nedeni, yaralanma zonu, eşlik eden hifema, fibrin reaksiyonu, iris prolapsusu, vitreus kaybı, ön ve arka kapsülün durumu, oküler travma skoru (OTS), ilk ve ikinci cerrahi arasındaki süre, yerleştirilen göz içi mercek (GIM) yeri, en iyi düzeltilmiş görme keskinliği (EIDGK) ve ek bulgular incelendi. Katarakt cerrahisi sonrası EiDGK'ne etki eden faktörler incelendi.

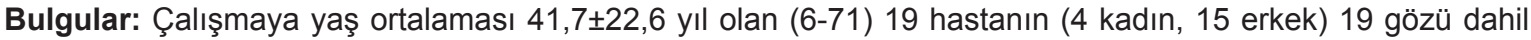
edildi. Hastaların 14'ünde $(\% 73,6)$ zon 1, 4'ünde $(\% 21)$ zon 2 , 1'nde $(\% 5,2)$ zon 3 yaralanma mevcuttu. İlk başvurduklarında hastaların 4'ünde (\%21) hifema, 7'sinde $(\% 36,8)$ fibrin reaksiyonu, 11 'inde $(\% 57,8)$ iris prolapsusu, 16'sında $(\% 84,2)$ lens ön kapsül hasarı, 5 'inde $(\% 26,3)$ vitreus kaybı mevcuttu. Hastaların başlangıç görmeleri ortalama $0,07 \pm 0,05(p+$ ile 0,6$)$ idi. OTS $2,4 \pm 0,7$ olarak hesaplandı. Hastaların 12 'sine $(\% 63,1)$ primer cerrahi onarım, 4'üne (\%21) primer onarım ve lens ekstraksiyonu, 3'üne $(\% 15,7)$ primer onarım, lens ekstraksiyonu ve göz içi mercek (GIM) implantasyonu yapıldı. Hastaların 14 'üne $(\% 73,6)$ primer onarımdan ortalama 69,1 $\pm 56,6$ (2-300) gün sonra lens ekstraksiyonu ve GiM implantasyonu yapıldı. $2(\% 10,5)$ hastaya GiM implantasyonu yapılamadı. Hastaların katarakt cerrahisi sonrası 1. ay EIDGK ortalama $0,5 \pm 0,3(0,05-0,9)$ düzeyinde olup; 20/40 ve üzerinde görme oranına sahip hastaların oranı \%52,6 idi. Hastaların 1. ay ElDGK ile başlangıç EiDGK arasında korelasyon mevcuttu ( $p: 0,044 ;$ r:0.467 Pearson korelasyon testi). Benzer olarak hastaların OTS ile 1. ay EIDGK arasında korelasyon mevcuttu ( $p: 0,015 ; r: 0,551$ Pearson korelasyon testi). Hastaların 2'sinde $(\% 10,5)$ antiglokomatözlerle kontrol altına alınan sekonder glokom gelişirken, 1 'inde $(\% 5,2)$ 1 ay içinde retina dekolmanı gelişti ve vitreoretinal cerrahi yapıldı.

Sonuç: Perforan göz yaralanmasına ikincil travmatik kataraktların görsel prognozunu; başlangıç görme düzeyi ve OTS etkilemektedir. Bu hastalarda hastanın klinik durumu yanında cerrahi planlama ve zamanlaması da önemlidir. Her olgu kendi klinik durumuna göre değerlendirilerek; yapılan en uygun cerrahi girişimle tatmin edici görsel sonuçlar alınmaktadır.

Anahtar Kelimeler:Perforan göz yaralanması, travmatik katarakt, katarakt cerrahisi.

Doğan E, Çelik E, Özkan Aksoy N, Köklü Çakır B, Bursalı Ö. Perforan göz yaralanmasına ikincil travmatik kataraktlarda katarakt cerrahisi sonuçları. Pam Tıp Derg 2019;12:303-308.

\begin{abstract}
Purpose:To evaluate the results of cataract surgery in patients with traumatic cataracts secondary to perforating eye injury.

Material and Methods: In this study the data of patients who underwent cataract surgery for traumatic cataract secondary to perforating eye injury between 2015-2018 were evaluated retrospectively. Age, gender, cause and localization of trauma, presence of hyphema, fibrin reaction, iris prolapse, vitreous loss, anterior and posterior capsule status, ocular trauma score (OTS), the time of cataract surgery, intraocular lens (IOL) localization, the best corrected visual acuity (BCVA) and additional symptoms were analyzed for each case. The factors affecting BCVA after cataract surgery were analyzed.
\end{abstract}

Emine Doğan, Op. Dr. Sakarya Eğitim ve Araştırma Hastanesi Göz Hastalıkları Kliniği, SAKARYA, e-posta: dremined@yahoo.com, (orcid. org/0000-0002-6505-3328. (Sorumlu yazar)

Erkan Çelik, Doç. Dr. Sakarya Eğitim ve Araştırma Hastanesi Göz Hastalıkları Kliniği, SAKARYA, e- posta: drerkancelik@gmail.com (orcid. org/0000-0002-8681-7868)

Nilgün Özkan Aksoy, Op. Dr. Sakarya Eğitim ve Araştırma Hastanesi Göz Hastalıkları Kliniği, SAKARYA, e- posta: nilgun_aksoy@yahoo.com (orcid.org/0000-0003-1107-9546)

Burçin Köklü Çakır, Op. Dr. Sakarya Eğitim ve Araştırma Hastanesi Göz Hastalıkları Kliniği, SAKARYA, e- posta: b_koklu@yahoo.com (orcid. org/0000-0001-7816-0627)

Özlem Bursalı, Op. Dr. Sakarya Eğitim ve Araştırma Hastanesi Göz Hastalıkları Kliniği, SAKARYA, e- posta: drozlemtas@yahoo.com (orcid. org/0000-0001-8535-5799) 
Results: The study included 19 eyes of 19 patients (15 men, 4 women) with a mean age of $41.7 \pm 22.6(6-71)$ years. Fourteen (73.6\%) patients had zone I, 4 (21\%) patients had zone II, 1 (5.2\%) patient had zone III injury. Four (21\%) patients had hyphema, 7 (36.8\%) patients had fibrin reaction, 11 (57.8\%) patients had iris prolapse, $16(84.2 \%)$ patients had anterior capsule damage, $5(26.3 \%)$ patients had vitreous loss in initial examination. The mean initial visual acuity was $0.07 \pm 0.05[p(+)-0.6]$ and OTS was $2.4 \pm 0.7$. Primary repair was performed in $12(63.1 \%)$ patients, primary repair and lens extraction was performed in $4(21 \%)$ patients, primary repair, lens extraction and IOL implantation was performed in $3(15.7 \%)$ patients. Lens extraction and IOL implantation was performed in $14(73.6 \%)$ patients, $69.1 \pm 56.6$ (2-300) days after primary reperation. IOL implantation could not be performed in $2(10.5 \%)$ patients. Mean BCVA was $0.5 \pm 0.3(0.05-0.9)$ one month after cataract surgery. $52.6 \%$ of patients achieved a final visual acuity of $\geq 20 / 40$. There was a correlation between initial and 1 . month BCVA ( $p: 0.044, r: 0.467$ Pearson correlation analyze). Similarly a correlation was found between OTS and BCVA (p:0.015, r:0.551, Pearson correlation analyze). In 2 patients (10.5\%) secondary glaucoma controlled with antiglacomatous was detected. One patient had retinal detachment within 1 month after surgery and vitreoretinal surgery was performed.

Conclusion:Initual visual acuity and OTS affects visual prognosis of traumatic cataracts secondary to perforating eye injuries. In these patients planning and timing of surgery are important as well as patients clinical condition. Satisfactory visual results are obtained with the most suitable surgical approach according to clinical condition of each patients.

Key Words: Perforating eye injury, traumatic cataract, cataract surgery.

Doğan E, Çelik E, Özkan Aksoy N, Köklü Çakır B, Bursalı Ö. The results of cataract surgery in traumatic cataracts secondary to perforating eye injury. Pam Med J 2019;12:303-308.

\section{Giriş}

Perforan göz travması en ciddi oküler travma tipi olup, ciddi görme kaybı ve iş gücü kaybına neden olan bir problemdir. Ciddi perforan göz yaralanmalarına hifema, iris prolapsusu, katarakt, iridodiyaliz gibi ön segment patolojileri ve vitreus hemorajisi, koroid rüptürü, retina dekolmanı gibi arka segment patolojileri eşlik edebilir. Perforan yaralanmalarda olguların $\% 27-\% 65$ 'inde travmatik katarakt olduğu bildirilmiştir [1] Travmatik katarakt ve eşlik eden diğer ön ve arka segment patolojileri uygulanacak olan cerrahi tekniği etkiler [2]. $\mathrm{Bu}$ olgularda katarakt cerrahisi sonrası görsel prognozda oküler travma tipi, eşlik eden diğer oküler doku hasarı, cerrahi teknikteki farklar gibi faktörlerin rolü vardır [1-3]. Cerrahi sonrası nihai görme, oküler travma sonrası hasarlanmış olma intimali yüksek olan kornea ve retinanın fonksiyonel bütünlüğüne fazlasıyla bağlıdır.

\section{Literatürde katarakt cerrahisinin} zamanlaması ve bunun görsel prognozla ilişkisi ile ilgili tam bir fikir birliği yoktur [3-6]. Travmatik katarakt olgularının bir kısmında katarakt desantralize ve ilerleme eğiliminde değilse takip edilebilir. Ancak kataraktın yoğun olduğu ve ön kapsül hasarı olan olgularda katarakt cerrahisi gerekmektedir. Katarakt cerrahisi açık glob yaralanmasının tamiri sırasında (primer) veya sonraki bir zamanda (sekonder) yapılabilir. Primer cerrahi lens proteinlerinin salınımına bağlı inflamasyonun önlenmesi, arka segment yapılarının daha iyi gözlenmesi gibi avantajlara sahipken; korneal ve/veya skleral yaranın genişliği, enfeksiyon olasılığı ve konulacak göz içi merceğin (GiM) biometrik ölçümünün güçlüğü gibi nedenlerle her zaman mümkün olmayabilir [3, 4]. Bazı olgularda göz perforan yaralanma tamirinin ardından uygun tedavilerle daha sakin duruma getirildikten sonra en uygun cerrahi prosedür ve GiM seçimiyle sekonder cerrahi tercih edilmektedir.

Çalışmamızda perforan göz yaralanmasına eşlik eden travmatik kataraktı olan olgularda katarakt cerrahisi sonuçlarının değerlendirilmesi ve hastaların görme prognozuna etki eden faktörlerin incelenmesi amaçlanmıştır.

\section{Gereç ve yöntem}

Çalışmamızda, 2015-2018 yılları arasında perforasyona ikincil travmatik katarakt nedeniyle cerrahi uygulanan olguların dosyaları geriye dönük olarak değerlendirildi. Çalışma Helsinki Deklerasyonu'nda yer alan etik prensiplerine uygun olarak gerçekleştirildi ve hastanemiz etik kurulundan izin alındı. Hasta dosyalarından yaş, cinsiyet, travma nedeni, yaralanma tipi, zonu, ilk başvuru anındaki en iyi düzeltilmiş görme keskinliği (EIDGK), eşlik eden hifema, fibrin reaksiyonu varlığı, ön ve arka kapsülün durumu, vitre kaybı olup olmadığı, yaralanma ile katarakt cerrahisi arasındaki süre, uygulanan cerrahi teknik, yerleştirilen Gi'M'in yeri, katarakt 
cerrahisi sonrası 1. ay EIDGK, cerrahi sonrası gelişen ek komplikasyonlar kaydedildi.

Mekanik yaralanmanın sınıflandırılmasında OTS grubunun Birmingham Göz Travma Terminolojisine dayanarak yaptığı sınıflandırma kullanıldı. Bu sınıflandırmaya dayanarak her hasta için OTS belirlendi.

Katarakt cerrahisi yaralanmanın durumuna göre perforan yaralanmanın tamirisırasında veya sonraki bir zamanda lensektomi, ekstrakapsüler katarakt ekstraksiyonu, fakoemülsifikasyon gibi çeşitli cerrahi yöntemlerle yapıldı. Hastalara operasyon sonrası topikal antibiyotik ve steroid tedavisi uygulandı. Hastalar operasyon sonrası 1.hafta ve 1.ayda kontrol edildi ve takiplerde Snellen eşeli ile EiDGK keskinliği, intraoküler basınç ölçüldü, biyomikroskop ile ön segment ve fundus muayenesi yapıldı.

İstatistiksel analiz SPSS 20 (SPSS Inc, Chicago, USA) programı ile yapıldı. 1.ay EIDGK ile başlangıç görme keskinliği ve OTS arasındaki ilişki Pearson korelasyon analizi ile analiz edildi.

\section{Bulgular}

Çalışmaya yaş ortalaması $41,7 \pm 22,6$ yıl olan (6-71) 19 hastanın (4 kadın, 15 erkek) 19 gözü dahil edildi. Hastaların 14'ünde zon I (\%73,6), 4'ünde (\%21) zon II, 1'nde $(\% 5,2)$ zon III yaralanma mevcuttu. Travmaya neden olan cisimler arasında 4 olguda (\%21) dal çarpması, 4 'ünde (\%21) demir, 4'ünde (\%21) künt travma, 2 'sinde $(\% 10,5)$ trafik kazası, 2'sinde $(\% 10,5)$ tel, 3'ünde $(\% 15,7)$ diğer cisimler (dart, dişli parçası, şemsiye) tespit edildi.

Illk başvurduklarında hastaların 4'ünde (\%21) hifema, 7 'sinde $(\% 36,8)$ fibrin reaksiyonu, 11 'inde $(\% 57,8)$ iris prolapsusu, 16'sında $(\% 84,2)$ lens ön kapsül hasarı, 5 'inde $(\% 26,3)$ vitreus kaybı mevcuttu (Tablo 1). Hastaların

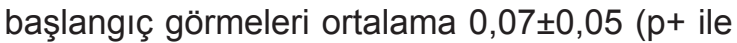
0,6 ) idi. OTS 2,4 $\pm 0,7$ olarak hesaplandı (Tablo 2).

Tablo 1. Olguların genel özellikleri.

\begin{tabular}{|c|c|c|}
\hline & $\mathrm{n}$ & $\%$ \\
\hline \multicolumn{3}{|l|}{ Travma nedeni } \\
\hline Dal & 4 & 21 \\
\hline Demir & 4 & 21 \\
\hline Künt & 4 & 21 \\
\hline Trafik kazası & 2 & 10,5 \\
\hline Tel & 2 & 10,5 \\
\hline Diğer & 3 & 15,7 \\
\hline \multicolumn{3}{|l|}{ Zon } \\
\hline 1 & 14 & 73,6 \\
\hline II & 4 & 21 \\
\hline III & 1 & 5,2 \\
\hline \multicolumn{3}{|l|}{ Eşlik eden ön- arka segment patolojileri } \\
\hline Hifema & 4 & 21 \\
\hline İris proplapsusu & 11 & 57,8 \\
\hline Fibrin reaksiyon & 7 & 36,8 \\
\hline Vitreus Kaybı & 5 & 26,3 \\
\hline Ön kapsül Hasarı & 16 & 84,2 \\
\hline Arka Kapsül Hasarı & 7 & 36,8 \\
\hline \multicolumn{3}{|l|}{ Cerrahi } \\
\hline Primer onarım & 12 & 63,1 \\
\hline Primer onarım+ lens ekstraksiyonu & 4 & 21 \\
\hline Primer onarım+ lens ekstraksiyonu +GiM İmplantasyonu & 3 & 15,7 \\
\hline \multicolumn{3}{|l|}{ GiM } \\
\hline Kapsül içi & 8 & 47 \\
\hline Sulkus & 9 & 52,9 \\
\hline
\end{tabular}

GiM: Göz içi mercek 
Tablo 2. Olguların genel klinik özellikleri.

\begin{tabular}{ll}
\hline & Ortalama \pm SD \\
\hline Yaş & $41,7 \pm 22,6$ \\
Başlangıç EiDGK & $0,07 \pm 0,05$ \\
OTS & $2,4 \pm 0,7$ \\
Süre* (gün) & $69,1 \pm 56,6$ \\
1.ay EiDGK & $0,5 \pm 0,3$ \\
\hline
\end{tabular}

EIDGK: En lyi Düzeltilmiş Görme Keskinliği, * Reperasyon ile katarakt cerrahisi arasında geçen süre.

Hastaların 12'sine $(\% 63,1)$ primer cerrahi onarım, 4'üne (\%21) primer onarım ve lens ekstraksiyonu, 3'üne $(\% 15,7)$ primer onarım, lens ekstraksiyonu ve GiM implantasyonu yapıldı. Hastaların 14'üne $(\% 82,3)$ primer onarımdan ortalama $69,1 \pm 56,6$ (2-300) gün sonra lens ekstraksiyonu ve GiM implantasyonu yapıldı. Yedi hastada $(\% 36,8)$ arka kapsülün bütünlüğünün bozulduğu belirlendi. Kullanılan GiM'lerin 9'u (\%52,9) sulkusa, 8' i (\%47) kapsül içine implante edildi. 2 hastaya GiM implantasyonu yapılamadı. Erken postoperatif komplikasyon olarak 4 hastada (\%21) ön kamarada fibrin reaksiyon gelişti.

Hastaların katarakt cerrahisi sonrası 1.ay EIDGK ortalama $0,5 \pm 0,3(0,05-0,9)$ idi. 1.ay kontroldeki ortalama sferik refraksiyon kusuru ortalaması 1,3 $\pm 0,8$ dioptri iken, ortalama astigmatizma 1,6 0 0,9 dioptri idi. Hastaların 1.ay EIDGK ile başlangıç EIDGK arasında korelasyon mevcuttu ( $p: 0,044 ;$ r:0,467 Pearson korelasyon testi). Benzer olarak hastaların OTS değeri ile 1.ay EIDGK arasında korelasyon mevcuttu ( $p: 0,015 ; r: 0,551$ Pearson korelasyon testi)

Son kontroldeki göz içi basıncı ortalama $15,8 \pm 3,6 \mathrm{mmHg}$ idi ve 2 hastada $(\% 10,5)$ antiglokomatözlerle kontrol altına alınan sekonder glokom gelişti. Hastaların 1'inde cerrahi sonrası 1 ay içinde gelişen retina dekolmanı nedeniyle vitreoretinal cerrahi uygulandı. Hastaların 2'sine $(\% 10,5)$ katarakt cerrahisi sonrası ilk bir yıl içinde YAG lazer ile arka kapsülotomi yapıldı.

\section{Tartışma}

Travmatik katarakt olgularına sıklıkla ön ve arka segmenti de içeren patolojiler eşlik ettiğinden, bu hastalarda katarakt cerrahisi ile görsel kazanımın sağlanması komplike bir durumdur $[2,7]$.

Çalışmamızda olgularımızın katarakt cerrahisi sonrası 1.ay EIDGK'si 0,5 $\pm 0,3$ düzeyinde olup; 20/40 veüzerindegörme oranına sahip hastaların oranı \%52,6 idi. Bu olgularda katarakt cerrahisi sonrası görsel kazanımı oküler travma tipi, eşlik eden diğer oküler doku hasarı, cerrahi teknikteki farklar gibi faktörler etkilemektedir [8, 9]. Qi ve ark 480 olgudan oluşan çalışmalarında katarakt cerrahisi sonrası $20 / 60$ ve daha iyi görme oranına sahip olanların oranını \%65,5 olarak bildirmiştir [9]. Gradin ve Yorston bu oranı \%64,7, Rogers ve ark. \%66,7, Shah ve ark \%54,3 olarak bildirmiştir [10-12]. Ülkemizde yapılan Yeter ve Güngör'ün yaptığı 16 olgudan oluşan bir çalışmada ortalama 1.ay EIDGK 0,49; 20/40 ve üzerinde görme oranına sahip olanların oranı ise $\% 57$ olarak bildirilmiştir [13]. Literatürde farklı sonuçlar çıkmasının nedeni çalışma gruplarında hasta sayılarının, oküler travma tipi ve cerrahinin ve eşlik eden diğer oküler dokuların hasarının farklı olmasına bağlı olabilir.

Katarakt cerrahisi sonrası görme düzeyi artmayan hastalarda korneada yer alan skara bağlı irregüler astigmatizma, eşlik eden retinal skar veya epiretinal membran gibi patolojiler bildirilmiştir [4].

Perforan göz travmalarında oküler travmanın tipi ve yeri de sonuç görme keskinliğini etkilemektedir. Açık glob yaralanmalarında görsel sonuç kapalı glob yaralanmalarına göre daha iyi bulunmuştur. Shah ve ark açık glob yaralanması olan olguların \%48'inde, kapalı glob yaralanması olanların \%29'unda 20/60 ve daha iyi görme olduğunu bildirmiştir [14]. Brar ve ark benzer olarak açık glob yaralanması olan olguların \%86,4'ünde, kapalı 
glob yaralanması olanların \%38,8'inde 20/40 ve daha iyi görme olduğunu bildirmiştir [8]. Oküler travmanın yeri değerlendirildiğnde; zon 1 yaralanmalarda görsel sonucun, zon 2 ve zon 3 yaralanmalara göre daha iyi olduğu bildirilmiştir [9]. Çalışmamızda hastaların çoğunda zon 1 yaralanma olduğundan; hastaları bu açıdan karşılaştırmak mümkün olmamıştır.

Çalışmamızda olgularımızın sonuç görme keskinliği başlangıç görme keskinliği ve OTS ile korele idi. Benzer olarak Shah ve ark. ve Zhu ve ark pediatrik travmatik katarakt olgularında OTS değeri ile sonuç görme keskinliğinin korele olduğunu bildirmiştir. [15, 16]. Qi ve ark. erişkin travmatik katarakt olgularını inceledikleri çalışmalarında OTS'nin bu olguların uzun süreli takibinde sonuç görme keskinliğini belirlemede yüksek sensivite ve spesifiteye sahip olduğunu bildirmiştir [9].

Travmatik katarakt olgularında katarakt cerrahisi açık glob yaralanmasının tamiri sırasında veya sonraki bir zamanda yapılabilir. Lensektomi, ekstrakapsüler katarakt ekstraksiyonu, fakoemülsifikasyon gibi çeşitli cerrahiler yapılabilir. Bu olguların çoğunda ön ve/veya arka kapsül bütünlüğü bozulduğu için cerrahi komplikasyon riski artmaktadır. Ayrıca cerrahi sırasında vitreus kaybı ve lens partiküllerinin vitreus ile teması olabileceğinden; arka segmente müdahale edilebilecek şekilde multidisipliner bir cerrahi yaklaşımla davranılması uygun olacaktır [7, 17].

Bu olgularda, primer ve sekonder cerrahinin birbirleri üzerindeki üstünlüğü olgudan olguya değişiklik göstermektedir. Primer cerrahi görsel rehabilitasyon sürecini hızlandırma gibi üstünlüğe sahip olmakla birlikte, yara yerinin genişliği, net görüntünün sağlanamaması ve GiM ölçümünde güçlük gibi nedenlerle her olguda yapılamamaktadır [1, 3]. Ayrıca bazı yayınlarda enfeksiyon, inflamasyon, göz içi basıncında yükselme gibi risklerin primer cerrahi ile arttığı bildirilmiştir [18, 19]. Bunun yanısıra literatürde primer cerrahi ile iyi görsel sonuçların alındığını bildiren yayınlar da vardır [5,6]. Rubsamen ve ark zon I yaralanması olan ve primer cerrahi yapılan olguların \%64'ünde $20 / 40$ ve daha iyi görme olduğunu bildirmiştir [6]. Sen ve ark pediatrik travmatik katarakt olgularında primer ve sekonder cerrahiyi karşılaştırdıkları 139 olguluk yayınlarında; iki grupta görsel sonuçların benzer olduğunu ve birbirlerine belirgin bir üstünlüğü olmadığını bildirmiştir [3]. Benzer olarak Tabatabaei ve arkadaşları da primer ve sekonder cerrahi arasında görsel sonuçlar, intraoperatif ve postoperatif komplikasyonlar açısından belirgin bir fark olmadığını bildirmiştir [1]. Çalışmamızda yara yerinin genişliği ve net görüntü sağlanamaması gibi nedenlerle sadece 3 olguda primer cerrahi uygulanmış olup; hastaları bu açıdan karşılaştırmak mümkün olmamıştır.

Literatürde travmatik katarakt olgularına GiM implantasyonu oranı \%81-94 arasındadır [2, 9, 13]. Bizim çalışmamızda bu oran $\% 89,4$ 'tür. 2 olguda travmaya ikincil santral korneal skar nedeniyle GiM konulamamıştır. Kapsülün destek durumuna göre GiM tercih edilmiş olup; kullanılan GiM'lerin 9'u (\%52,9) sulkusa, 8'i (\%47) kapsül içine implante edilmiştir. Kapsül desteği olmayan olgularda skleral fiksasyon GiM, iris fikse veya ön kamara GìM kullanılabilir.

Cerrahi sonuçlar çok iyi olsa bile uzun dönemde endoftalmi, glokom, retina dekolmanı gibi çeşitli komplikasyonlarla karşılaşılabilir. Brar ve ark oküler travma sonrası postoperatif komplikasyonların cerrahi sonrası görmeyi etkileyen en önemli faktör olduğunu bildirmiştir [8]. Olgularımızın 2'sinde $(\% 10,5)$ antiglokomatözlerle kontrol altına alınan sekonder glokom gelişmiştir. Glokom bu olgularda açı resesyona, iris travmasına, lens luksasyonuna bağlı olarak veya sekonder olarak ortaya çıkabilir. Genellikle ilk 6 ay içinde ortaya çıkmaktadır ve zon II yaralanma, penetran keratoplasti ve vitreus hemorajisi glokom riskini artırmaktadır [20]. Olgularımızın 1'inde 1 ay içinde gelişen retina dekolmanı nedeniyle vitreoretinal cerrahi uygulanmıştır. Retina dekolmanı bu olguların \%15-32'sinde görülebilir ve göz içi yabancı cisim varlığı, özellikle genç olgularda gözlenebilen proliferatif vitreoretinopati riski artırır [21].

Sonuç olarak perforan göz yaralanmasına ikincil travmatik katarakt olgularının görsel prognozunda başlangıç görme düzeyi ve OTS önemlidir. Bu olguların cerrahisinde en iyi görsel sonucun alınması için her olgu kendi şartları içinde özel olarak değerlendirilmeli ve hastanın klinik durumuna en uygun cerrahi planlama ve zamanlama yapılmalıdır. Uygun cerrahi girişim ve takiple iyi görsel sonuçlar alınabilmektedir. 
Çıkar İlişkisi: Yazarlar çıkar ilişkisi olmadığını beyan eder.

\section{Kaynaklar}

1. Tabatabaei SA, Rajabi MB, Tabatabaei SM, Soleimani $M$, Rahimi F, Yaseri M. Early versus late traumatic cataract surgery and intraocular lens implantation. Eye 2017;31:1199-1204. https://doi.org/10.1038/ eye.2017.57

2. Shah M, Shah S, Shah S, Prasad V, Parikh A. Visual recovery and predictors of visual prognosis after managing traumatic cataracts in 555 patients. Indian J Ophthalmol 2011;59:217-222. https://doi. org/10.4103/0301-4738.81043

3. Sen P, Shah C, Sen A, Jain E, Mohan A. Primary versus secondary intraocular lens implantation in traumatic cataract after open-globe injury in pediatric patients. J Cataract Refract Surg 2018;44:1446-1453. https://doi. org/10.1016/j.jcrs.2018.07.061

4. Chuang LH, Lai CC. Secondary intraocular lens implantation of traumatic cataract in open-globe injury. Can J Ophthalmol 2005;40:454-459.

5. Moisseiev J, Segev F, Harizman N, Arazi T, Rotenstreich Y, Assia El. Primary cataract extraction and intraocular lens implantation in penetrating ocular trauma. Ophthalmology 2001;108:1099-1103.

6. Rubsamen PE, Irvine WD, McCuen BW, Smiddy WE, Bowman CB. Primary intraocular lens implantation in the setting of penetrating ocular trauma. Ophthalmology 1995;102:101-107.

7. Caciula D, Gavriș M, Tamașoi I. Penetrating corneal wound with traumatic cataract and intraocular foreign body-case report. Rom J Ophthalmol 2017;61:54-59.

8. Brar GS, Ram J, Pandav SS, Reddy GS, Singh U, Gupta A. Postoperative complications and visual results in uniocular pediatric traumatic cataract. Ophthalmic Surg Lasers 2001;32:233-238.

9. Qi Y, Zhang YF, Zhu Y, Wan MG, Du SS, Yue ZZ. Prognostic Factors for Visual Outcome in Traumatic Cataract Patients. J Ophthalmol 2016;2016:1748583. https://doi.org/10.1155/2016/1748583

10. Gradin D, Yorston D. Intraocular lens implantation for traumatic cataract in children in East Africa. J Cataract Refract Surg 2001;27:2017-2025.

11. Rogers G, Mustak H, Hann M, Steven D, Cook C. Sutured posterior chamber intraocular lenses for traumatic cataract in Africa. J Cataract Refract Surg 2014;40:1097-1101. https://doi.org/10.1016/j. jcrs.2014.01.031

12. Shah MA, Shah SM, Shah SB, et al. Comparative study of final visual outcome between open- and closed-globe injuries following surgical treatment of traumatic cataract. Graefes Arch Clin Exp Ophthalmol 2011;249:1775-1781. https://doi.org/10.1007/s00417011-1732-7
13. Yeter V, Güngör İ. Visual outcomes and timing of surgery on traumatic cataract cases. J Exp Clin Med 2012;29:93-96

14. Shah MA, Shah SM, Gosai SR, et al. Comparative study of visual outcome between open- and closedglobe injuries following surgical treatment of traumatic cataract in children. Eur J Ophthalmol 2018;28:406411. https://doi.org/10.1177/1120672117747021

15. Shah MA, Shah SM, Applewar A, Patel C, Patel K. Ocular Trauma Score as a predictor of final visual outcomes in traumatic cataract cases in pediatric patients. J Cataract Refract Surg 2012;38:959-965. https://doi.org/10.1016/j.jcrs.2011.12.032

16. Zhu L, Wu Z, Dong $F$ et al. Two kinds of ocular trauma score for paediatric traumatic cataract in penetrating eye injuries. Injury 2015;46:1828-1833. https://doi. org/10.1016/j.injury.2015.04.024

17. Kuhn F. Traumatic cataract: what, when, how. Graefes Arch Clin Exp Ophthalmol 2010;248:1221-1223. https://doi.org/10.1007/s00417-010-1387-9

18. Lamkin JC, Azar DT, Mead MD, Volpe NJ. Simultaneous corneal laceration repair, cataract removal, and posterior chamber intraocular lens implantation. Am J Ophthalmol 1992;113:626-631.

19. Andreoli CM, Andreoli MT, Kloek CE, Ahuero AE, Vavvas D, Durand ML. Low rate of endophthalmitis in a large series of open globe injuries. Am J Ophthalmol 2009;147:601-608. https://doi.org/10.1016/j. ajo.2008.10.023

20. Bojikian KD, Stein AL, Slabaugh MA, Chen PP. Incidence and risk factors for traumatic intraocular pressure elevation and traumatic glaucoma after open-globe injury. Eye 2015;29:1579-1584. https://doi. org/10.1038/eye.2015.173

21. Mahapatra SK, Rao NG. Visual outcome of pars plana vitrectomy with intraocular foreign body removal through sclerocorneal tunnel and sulcus-fixated intraocular lens implantation as a single procedure, in cases of metallic intraocular foreign body with traumatic cataract. Indian J Ophthalmol 2010;58:115-118. https:// doi.org/10.4103/0301-4738.60077

Bu çalışma için Sakarya Üniversitesi Etik KuruIu'nun 03.01.2019 tarih ve E.69 sayısı ile onay verilmiştir. 